\title{
ANALISIS FUNGSI DAN MAKNA SUNTIANG DALAM PAKAIAN ADAT MINANGKABAU
}

\author{
Wira Gusti Mustika ${ }^{1 *}$, Budiwirman ${ }^{*}$ \\ Program Studi Pendidikan Ilmu Pengetahuan Sosial Konsentrasi Pendidikan Seni dan Budaya \\ Program Pascasarjana \\ Universitas Negeri Padang \\ Jl. Prof. Dr. Hamta, Air Tawar Padang, Kel. Air Tawar Barat, Kec. Padang Utara, Kota Padang, Kode Pos 25171 \\ Sumatera Barat. Indonesia \\ Email: wiradenira@gmail.com
}

\begin{abstract}
Abstrak
Suntiang merupakan salah satu elemen terpenting dalam kelengkapan pakaian adat perkawinan. Tujuan penelitaian ini adalah untuk mengetahui fungsi dan makna Suntiang dalam pakaian adat Minangkabau. Penelitian ini menggunakan jenis penelitian kualitatif. Teknik pengumpulan data menggunakan observasi dan studi literature. Hasil penelitian ini adalah Suntiang adalah perhiasan kepala bertingkat berwarna keemasan yang dipakai oleh perempuan Minangkabau. Hiasan ini berbentuk setengah lingkaran yang terdiri dari susunan ornamen bermotif flora dan fauna, di antaranya diambil dari bentuk bunga mawar, pisang, burung merak, kupu-kupu, dan ikan. Ukuran suntiang berbeda menurut pemakaiannya. Berat suntiang berkisar antara 3,5 sampai $5 \mathrm{~kg}$. Namun, belakangan suntiang dibuat dengan ukuran lebih kecil dan bahan yang lebih ringan untuk memudahkan proses pembuatan dan pemakaian. Suntiang yang berat tersebut melambangkan beratnya tanggung jawab yang akan diemban oleh seorang wanita (Ibu/bundo) minang setelah menikah nanti. Walaupun berat saat dikenakan tetapi si pemakai suntiang Anak Daro (Mempelai wanita) tetap terlihat anggun, sopan dan feminim. Memakai suntiang ini juga jadi kebanggaan tersendiri bagi setiap wanita Minangkabau saat melangsungkan pernikahan. Bentuk sutiang kipas dengan warna emas terang dan perak. Suntiang yang asli biasanya terbuat dari bahan emas, perak dan tembaga tetapi untuk saat ini sudah banyak di modifikasi seperti menggunakan bahan aluminium yang di sepuh. Modifikasi ini dilakukan karena suntiang yang terbuat dari logam, (emas, perak, dan tembaga serta aluminium) sangatlah berat bila dikenakan dalam waktu yang lama. Baca juga Makna dan Arti Filosofi Pakaian Penghulu atau Datuk di Minangkabau.
\end{abstract}

Kata Kunci: suntiang, pakaian adat, minangkabau.

\begin{abstract}
Suntiang is one of the most important elements in the completeness of traditional wedding attire. The purpose of this research is to find out the function and meaning of Suntiang in Minangkabau traditional clothes. This research uses qualitative research. Data collection techniques using observation and literature study. The results of this study are Suntiang is a gold-colored multilevel headdress worn by Minangkabau women. This decoration is in the form of a half circle which consists of a floral and fauna patterned ornament, which is taken from the form of roses, bananas, peacocks, butterflies, and fish. The weight of suntiang ranges from 3.5 to $5 \mathrm{~kg}$. However, lately suntiang is made with smaller sizes and lighter materials to facilitate the process of making and using. The heavy weight symbolizes the weight of responsibility that will be carried out by a woman (mother / bundo) Minang after marriage later. Although heavy when worn, but the user suntiang Anak Daro (Bride) still looks elegant, polite and feminine. Wearing this suntiang is also a matter of pride for every Minangkabau woman when she gets married. A fan shape with bright gold and silver colors. The original Suntiang is usually made of gold, silver and copper, but for now it has been modified a lot, such as using aluminum which is coated. This modification is done because suntiang made of metal, (gold, silver, and copper and aluminum) is very heavy when worn for a long time. Also read the Meaning and Meaning of the Penghulu or Datuk Clothing Philosophy in Minangkabau.
\end{abstract}

Keywords: suntiang, traditional clothes, minangkabau.

\section{PENDAHULUAN}

Indonesia mempunyai adat istiadat dan pakaian yang berbeda setiap daerah mempunyai kekhasan tersendiri, keunikan dan berbeda dengan daerah lain yang mendiami berbagai macam daerah yang terbentang dari ujung sumatera sampai ujung selatan Irian jaya. 
Salah satu daerahnya adalah Minangkabau tepatnya di Kabupaten Padangpariaman pernikahan telah diatur dalam adat perkawinan, termasuk juga di dalamnya tata cara dan kelengkapan dalam berpakaian khususnya untuk kedua mempelai. Bagian yang menarik dari kelengkapan pakaian pengantin adalah suntiang.

Suntiang mempunyai arti penting dalam kehidupan sosial masyarakat Padangpariaman. Karena dalam adat perkawinan suntiang adalah sebagai simbol dari seorang pengantin perempuan (anak daro), dan melalui suntiang orang akan lebih cepat mengenal siapa pengantinnya.

Penggunaan suntiang sudah banyak yang praktis saat ini, karena sudah ditata dan dirangkai langsung oleh pengrajinnya, hal ini tidak hanya meringankan pekerjaan si penata rias tetapi juga sangat meringankan bagi pengantinya.

Berbeda dengan suntiang pada tahun 90-an yang penggunaanya sangat merepotkan, tidak hanya beratnya tetapi juga cara pemakaiannya yang kadangkala jika pemasangannya tidak benar bisa mencederai kulit kepala pengantinnya.

Suntiang gadang memiliki tampilan yang sangat menarik, nilai keindahan yang dimilikinya tidak saja terpancar dari warnanya akan tetapi juga didukung oleh keberagaman hiasan yang tertata di dalamnya secara visual. Beraneka macam hiasan tersebut tidak saja bertujuan untuk memberi keindahan dan kecantikan si pemakainya, namun terkandung pesan moral untuk kedua mempelaidan akan menjadi panutan dalam kehidupan berumah tangga. Berdasarkan uraian di atas, peneliti tertarik untuk membahas tentang Analisis Fungsi dan Makna Suntiang dalam pakaian adat Minangkabau. Tujuan penelitian ini adalah untuk mengetahui fungsi dan makna Suntiang dalam pakaian adat Minangkabau.

\section{KAJIAN TEORI}

\section{Busana}

Kata 'busana' oleh S. Woyowasito dikatakan berasal dari bahasa Sansekerta 'busana', dalam bahasa Indonesia kata 'busana' berarti pakaian (yang indahindah) Secara harfiah 'busana' juga berarti pakaian yang lengkap, pakaian yang mulia. Busana dapat dikatakan berfungsi untuk memperindah dan menambah kesan mulia kepada seseorang yang menggunakannya. Busana merupakan segala sesuatu yang kita gunakan mulai dari kepala sampai ke ujung kaki. Dalam hal ini termasuk : (1) semua benda yang melekat di badan seperti baju, sarung dan kain panjang, (2) semua benda yang melengkapi dan
Gorga Jurnal Seni Rupa

Volume 08 Nomor 02 Juli-Desember 2019 p-ISSN: 2301-5942 | e-ISSN: 2580-2380

berguna bagi si pemakai seperti selendang, topi, sarung tangan, kaos kaki, sepatu, tas, ikat pinggang, di dalam istilah asing disebut millineris, ( 3) semua benda yang gunanya menambah keindahan bagi si pemakai, seperti hiasan rambut, giwang, kalung, bros, gelang dan cincin, di dalam istilah asing lebih dikenal dengan istilah accessories. Fungsi dari busana adalah: (1) memenuhi kebutuhan kesusilaan dan kebudayaan suatu bangsa yang berkebudayaan dan menunjang tinggi kesusilaan, pasti menempatkan busana sebagai kebutuhan utama, (2) memenuhi kebutuhan kesehatan Busana gunanya untuk melindungi badan dari udara dingin, panas, angin (artinya sesuai dengan iklim), (3) memenuhi kebutuhan keindahan, artinya busana dapat membuat diri seseorang kelihatan indah, dapat menutupi bagian-bagian badan yang kurang ideal.

\section{Suntiang}

Suntiang merupakan salah satu bentuk hiasan kepala anak daro atau pengantin perempuan. Pada umumnya Suntiang yang sekarang biasa digunakan disebut suntiang gadang. Nama ini agar berbeda dengan suntiang ketek yang biasa dipakai oleh pendamping pengantin yang disebut pasumandan. Sunting gadang berbeda dengan sunting ketek dalam hal jumlah tingkat dari penyusunan hiasan di kepala. Jumlah tinggkat kembang goyang suntiang pada pengantin wanita minang ini biasanya ganjil. Jumlah tingkat suntiang yang paling tinggi adalah sebelas tingkat sedang yang paling rendah tujuh tingkat. Ada empat jenis hiasan yang disusun membentuk suntiang pada hiasan kepala pengantin minang ini. Lapisan yang paling bawah adalah deretan bungo sarunai. 3-5 lapis bungo sarunai ini membentuk dasar bagi sunting minang. Kemudian diletakkan deretan bunga gadang sebanyak 3 - 5 lapis. Hiasan yang paling atas adalah kambang goyang. Sedangkan hiasan sunting yang jatuh di pipi kanan dan pipi kiri pengantin minang ini disebut kote-kote. (Ibrahim, 1985: 120).

\section{METODE PENELITIAN}

Jenis penelitian yang digunakan adalah penelitian kualitatif. Menurut Bogdan dan Taylor (Moleong, 2005:4) menyatakan bahwa penelitian kualitatif adalah sebagai prosedur penelitian yang menghasilkan data deskriptif berupa kata-kata tertulis atau lisan dari orang-orang dan perilaku yang diamati. Adapun teknik pengumpulan data yang digunakan oleh peneliti yaitu Library research (studi kepustakaan) dan Internet Research. Langkah-langkah analisis data yang digunakan dalam penelitian ini yaitu Reduksi Data (Data Reduction), Display Data (Data Display), Analisis Perbandingan (Komparatif) dan Penarikan 


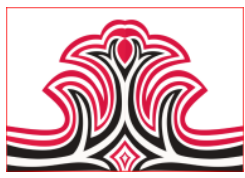

Kesimpulan (Conclusion

(Moleong, 2011).

\section{HASIL DAN PEMBAHASAN}

\section{Hasil}

\section{1). Desain Suntiang}

\section{(1). Motif}

Motif sunting bungo sanggul adalah suatu bentuk nyata yang digunakan untuk menambah tampilan sunting yang menggunakan elemen-elemen berdasarkan pada pola yang diinginkan. di Kenagarian Koto Baru Kecamatan Kubung Kabupaten Solok motif sunting yang dipakai yaitu motif bunga cempaka, motif bunga melati, motif bunga mawar, motif bunga kecubung, dan ditambahkan dengan hiasan akar sulur, motif burung walet, motif burung kakak tua dan motif kupu-kupu.

Motif bunga cempaka yang dibuat sebagai hiasan sunting bungo sanggul adalah melambangkan bahwa motif bunga cempaka itu merupakan suatu tanaman bunga yang banyak adanya di daerah Koto Baru, maka dengan adanya tanaman bunga cempaka tersebut dituangkan kedalam tampilan sunting bungo sanggul yang telah disusun seindahnya.

Motif bunga melati seorang perempuan itu ratu sehari yang harus dihiasi dengan yang bunga yang indah, yang seakan akan seorang pengantin tersebut berada diantara taman bunga yang indah. Motif bunga mawar melambangkan bahwa adanya tanggung jawab seorang perempuan terhadap pasangannya. Motif bunga kecubung melambangkan bahwa adanya suatu tingkatan kewajiban yang harus dipenuhi oleh seorang perempuan.

Hiasan yang dipakai pada suntiang bungo sanggul yaitu hiasan akar sulur yang melambangkan bahwa beratnya tanggung jawab seorang perempuan terhadap pasangannya, nan melambangkan liku-liku kehidupan kelaknya. Motif burung walet melambangkan bahwa adanya suatu kekhasan di daerah Koto Baru ini sebagai ciri khas yang dipakai pada motif suntiang bungo sanggul. Karena di Koto Baru terdapat banyak terdapat burung walet. Sedangkan untuk hiasan kupukupu melambangkan bahwa adanya keindahan disetiap perjalanan disetiap kehidupan kedua mempelai.

\section{(2).Bentuk/Model}

Bentuk suntiang yaitu berbentuk segitiga bagian depan, dan apabila suntiang dibentangkan akan berbentuk dua dimensi yaitu bentuk trapesium yang melambangkan adanya kaitan dengan rumah gadang
Gorga Jurnal Seni Rupa

Volume 08 Nomor 02 Juli-Desember 2019 p-ISSN: 2301-5942 | e-ISSN: 2580-2380

bagonjong di Minangkabau, makanya untuk bagian belakang dibuat seperti meruncing sebanyak enam buah gonjong yang mempunyai motif sama dengan motif pada bagian depan motif bunga cempaka. pada bagian belakang dan depan tetap berbentuk segitiga.

Bentuk segitiga melambangkan perempuan harus tampil cantik ketika memakai suntiang, maksudnya setiap perempuan memakai suntiang membentuk segitiga kebagian depan, untuk membentuk keindahan wajah seorang pengantin, ditambah dengan hiasan burung walet yang melambangkan bahwa setiap perempuan di Minangkabau sudah memiliki batasanbatasan dalam menjalani kehidupan berumah tangga nantinya. dan hiasan akar sulur yang melambangkan motif nan dipakai yaitu motif akar sulur bahwa jalan hidup dan liku-liku kehidupan rumah tangga yang akan ditempuh oleh seorang anak daro.

Menurut Puti Raudha Thaib (2014: 3) "menyatakan bahwa Suntiang yang digunakan sebagai kekhasan pengantin Minangkabau, kembang-kembang suntiang ini umumnya bertingkat dengan ganjil dimulai dari tujuh tingkat hingga sebelas tingkat”. Ada juga suntiang bertingkat mulai dari tiga hingga lima yang biasanya digunakan untuk pendamping pengantin atau dikenal juga dengan sebutan Pasumandan. Namun karena alasan kepraktisan dan menyesuaikan dengan bentuk wajah, tingkatan pada Suntiang dipertahankan ganjil namun jumlah tingkatannya disesuaikan dengan kemampuan dan kemauan si pengantin.

\section{Pembahasan}

Suntiang adalah simbol kebesaran anak daro di Minangkabau, khususnya di Kabupaten Padangpariaman. Untuk melewati masa peralihan dari remaja menjadi perempuan dewasa yang memiliki keluarga kecil sendiri, sang perempuan harus mengikuti berbagai acara adat perkawinan.

Suntiang merupakan pencampuran budaya cina dan masyarakat setempat, (Mutia, 2000:41). Sampai saat ini telah menjadi bagian dari budaya masyarakat Padangpariaman bahkan telah meluas ke seluruh wilayah Minangkabau. Hal ini terjadi tidak terlepas dari keindahan warna dan keberagamana hiasan yang ada dalam suntiang tersebut.

Ragam hias yang dijadikan sebagai elemen pembentuk suntiang umumnya terinspirasi dari apa yang ada di lingkungan alam sekitarnya, baik yang ada di darat, di udara maupun di laut. Sesuai dengan falsafah hidup masyarakat Minangkabau pada umumnya yaitu Alam 


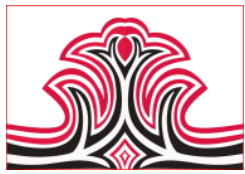

takambang jadi guru, bahwa semua yang ada di alam luas dapat dijadikan guru atau contoh.

Pemakaian suntiang bagi anak daro adalah salah satu bentuk gambaran tanggung jawab yang besar yang akan dipikul dipundak anak daro baik itu tanggungjawab dalam rumah tangga, keluarga maupun lingkungannya. Di dalam rumah tangga si perempuan berperan sebagai seorang istri bagi suaminya dan ibu bagi anak-anaknya yang harus menjaga keutuhan rumah tangganya. yang bermaanfaat bagi kehidupan manusia.

Di dalam masyarakat, perempuan yang sudah menikah akan diberi julukan bundo kanduang. Bundo kanduang adalah seorang perempuan yang memiliki sifat arif dan bijaksana yang menjadi tauladan bagi anak kemenakannya khususnya yang perempuan.

Makna filosofis yang terkandung pada sunting bungo sanggul yaitu Bentuk segitiga pada bagian depannya melambangkan pucuk pimpinan orang yang tiga sejalan dalam adat. Ada yang mengatur pusaka, ada yang mengatur syarak, dan ada juga yang mengatur adat didalam nagari. Tungku tiga sejalan merupakan pucuk tertinggi didalam adat. Bunga maksudnya wanita yang melambangkan sebagai makanan untuk burung.

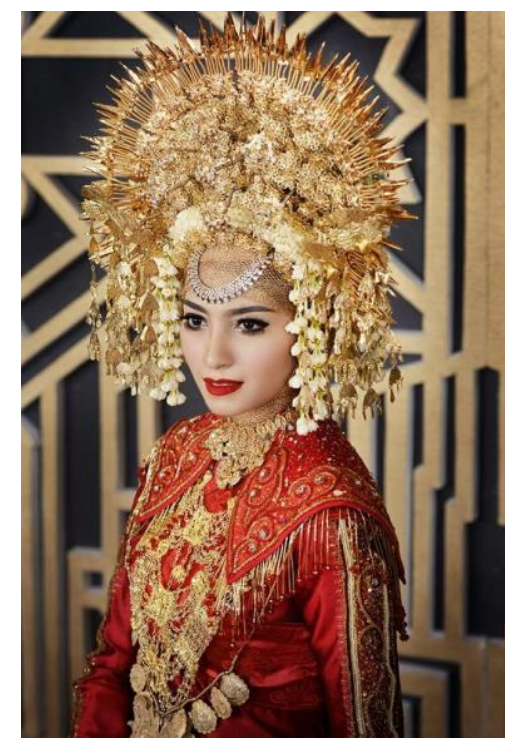

Gambar 1. Suntiang Gadang (Sumber: Wira Gusti Mustika, 2019)

\section{KESIMPULA DAN SARAN}

\section{Kesimpulan}

Suntiang merupakan salah satu elemen terpenting dalam kelengkapan pakaian adat perkawinan. Suntiang adalah perhiasan kepala bertingkat berwarna keemasan
Gorga Jurnal Seni Rupa

Volume 08 Nomor 02 Juli-Desember 2019 p-ISSN: 2301-5942 | e-ISSN: 2580-2380

yang dipakai oleh perempuan Minangkabau. Hiasan ini berbentuk setengah lingkaran yang terdiri dari susunan ornamen bermotif flora dan fauna, di antaranya diambil dari bentuk bunga mawar, pisang, burung merak, kupu-kupu, dan ikan.

Ukuran suntiang berbeda menurut pemakaiannya. Suntiang yang dipakai pengantin perempuan memiliki ukuran besar atau disebut suntiang gadang, sedangkan suntiang berukuran kecil atau suntiang ketek dipakai oleh pendamping pengantin perempuan. Berat suntiang berkisar antara 3,5 sampai $5 \mathrm{~kg}$. Namun, belakangan suntiang dibuat dengan ukuran lebih kecil dan bahan yang lebih ringan untuk memudahkan proses pembuatan dan pemakaian.

Suntiang yang berat tersebut melambangkan beratnya tanggung jawab yang akan diemban oleh seorang wanita (Ibu/bundo) minang setelah menikah nanti. Walaupun berat saat dikenakan tetapi si pemakai suntiang Anak Daro (Mempelai wanita) tetap terlihat anggun, sopan dan feminim. Memakai suntiang ini juga jadi kebanggaan tersendiri bagi setiap wanita Minangkabau saat melangsungkan pernikahan.

Bentuk sutiang kipas dengan warna emas terang dan perak. Suntiang yang asli biasanya terbuat dari bahan emas, perak dan tembaga tetapi untuk saat ini sudah banyak di modifikasi seperti menggunakan bahan aluminium yang di sepuh. Modifikasi ini dilakukan karena suntiang yang terbuat dari logam, (emas, perak, dan tembaga serta aluminium) sangatlah berat bila dikenakan dalam waktu yang lama. Baca juga Makna dan Arti Filosofi Pakaian Penghulu atau Datuk di Minangkabau.

\section{Saran}

Sebagai langkah untuk melestarikan dan menjaga eksistensi dari kesenian ini,diperlukanya kajian ilmiah dalam bentuk seminar ataupun workshop dan juga pertunjukan yang dapat meningkatkan kesadaran kolektif masyarakat terhadap pentingnya menjaga eksistensi dari sebuah kesenian masyarakat agar tidak hilang.

\section{DAFTAR RUJUKAN}

Ibrahim, Anwar, dkk (1985). Pakaian Adat Daerah Sumatera Barat. Padang: Depdikbud.

Moleong, Lexy. J. (2011). Metodologi Penelitian Kualitatif. Bandung: PT Remaja Rosdakarya.

Mutia, Riza, dkk. (2000). "Upacara Adat Perkawinan di Padangpariaman. Laporan Penelitian. Padang: Proyek Pembinaan Permusiuman Sumatera Barat. 
Raudha Taib, P.R. (2014). Pakaian Adat Perempuan
Minangkabau.
Padang:
Bundo

Kanduang,Provinsi Sumatera Barat. 